\title{
Os Elementos do Fantástico na Moderna Fiç̧ão Moçambicana: Ualalapi de Ungulani Ba Ka Khosa
}

\section{Fantastic Elements in the Modern Mozambican Fiction: Ualalapi by Ungulani Ba Ka Khosa}

\author{
Kristína Ceferová [k.ceferova@gmail.com] \\ Univerzita Palackého v Olomouci, República Checa
}

\section{RESUMO}

O romance Ualalapi (1987), de autoria do escritor moçambicano Ungulani Ba Ka Khosa (1957), tem como objetivo principal a subversão do discurso oficial sobre a personagem histórica de Ngungunhane, o último imperador de Gaza. O autor nesta narrativa histórica desenvolve o tema da relação entre a tradição e a modernidade, enfatizando o lugar da oralidade na realidade africana. O romance apresenta vários elementos que derivam da tradição e que formam parte de cosmovisão mitológica animista, típica da cultura africana. Estes elementos, tendo um carácter extraordinário, insólito, e sendo originados numa ordem não racional, podem ser denominados fantásticos. O artigo pretende refletir sobre o caráter e o lugar dos elementos fantásticos no romance Ualalapi e na narrativa moçambicana moderna.

\section{Palavras-Chave}

literatura moçambicana; elementos do fantástico; Ungulani Ba Ka Khosa; Ualalapi

\section{Abstract}

The novel Ualalapi (1987), by the Mozambican writer Ungulani Ba Ka Khosa (1957), chooses the subversion of the official discourse on the historical character of Ngungunhane, the last emperor of Gaza, as its main objective. In this historical narrative, the author is developing the theme of the relationship between tradition and modernity, emphasizing the place of orality in African reality. The novel presents several elements that are derived from the Mozambican tradition and form part of the animistic mythological worldview, typical for the African culture. These elements, having an extraordinary, unusual character and originating in a non -rational order, can be considered fantastic. The article intends to reflect on the character and the place of the fantastic elements in the novel Ualalapi and in the modern Mozambican narrative.

\section{KEYWORDS}

Mozambican literature; fantastic elements; Ungulani Ba Ka Khosa; Ualalapi

RECEBIDO 2019-03-04; ACEITE 2019-06-30

Este artigo teve o apoio financeiro do projeto do Ministério da Educação da República Checa IGA_ FF_2018_015. 
O presente trabalho pretende refletir sobre o romance Ualalapi (1987), da autoria do escritor moçambicano Ungulani Ba Ka Khosa (1957-), centrando-se no caráter dos elementos do fantástico que se apresentam na obra. $\mathrm{O}$ fantástico literário foi tradicionalmente identificado e reconhecido como surgimento de uma situação em que o mundo dirigido pela lógica, pelas leis racionais que todos compartimos, é invadido por um acontecimento, ser ou objeto fora das leis do mesmo mundo. Em outras palavras, foi definido como uma rutura, violação da ordem estabelecida no mundo quotidiano. Todorov na Introdução à literatura fantástica (1970) aprofunda a definição:

Aquele que o [acontecimento sobrenatural] percebe deve optar por uma das soluções possíveis; ou se trata de uma ilusão de sentidos, de um produto da imaginação e nesse caso as leis desse mundo continuam a ser o que são; ou então o acontecimento realmente ocorreu, é parte integrante da realidade, mas neste caso a realidade é regida por leis desconhecidas por nós. (Todorov 2007: 30)

Neste sentido, para Todorov, o fantástico ocupa o tempo de incerteza, o tempo de vacilação que um ser experimenta até escolher a explicação racional ou a irracional do acontecimento sobrenatural. Escolhendo a primeira opção, segundo o autor, a narrativa abandona o campo do fantástico e entra no gênero vizinho - o estranho; ao escolher a segunda explicação a narrativa é transferida para o gênero maravilhoso.

A maior parte da crítica literária que se ocupou com o estudo da literatura fantástica coincidiu em que o fantástico pode ser definido pela sua capacidade de produzir a sensação de medo no leitor. Ana González Salvador (1984) e Jaime Alazraki (1990) referem nos seus estudos nomes dos autores como P. G. Castex, L. Vax, R. Caillois, P. Penzoldt e H. P. Lovecraft que sublinham o temor como uma condição fundamental para a existência do gênero. Porém, já Todorov argumenta que "O medo está freqüentemente ligado com o fantástico, mas não como condição necessária” (2007: 41).

Além disso, como constata González Salvador, os autores que ela menciona no seu trabalho limitam a existência do gênero fantástico temporalmente para o século XIX e geograficamente para a literatura europeia e norte-americana (1984: 210). Em conseguinte, surge a questão de como definir o fantástico moderno, o fantástico proveniente dos séculos XX e XXI, em que não se manifesta a necessidade de produzir temor nos seus leitores e que não se apresenta como uma rutura da ordem estabelecida. González Salvador explica que o fantástico que se começou a escrever no século passado se caraterizou pelo "desvanecimento das fronteiras entre a fantasia e a realidade" e pelo feito de revestir "novas formas engendrando uma nova temática” (1984: 224).

Para se referir ao fantástico moderno, Jaime Alazraki aplica uma nova denominação - "o neofantástico" - e determina três pontos que o diferenciam do seu antecedente:

[Los denomino] Neofantásticos porque a pesar de pivotear alrededor de un elemento fantástico, estos relatos se diferencian de sus abuelos de siglo XIX por su visión, intención y su modus operandi. [...] Por su visión [...] porque lo neofantástico asume el mundo real como una máscara, como un tapujo que oculta una segunda realidad que es el verdadero destinatario de la narración neofantástica. [...] En lo que toca a la intención, el empeño del relato fantástico dirigido a provocar un miedo en el lector, un terror durante el cual trastabillan sus supuestos lógicos, no se da en el cuento neofantástico. [...] Finalmente, en lo que toca a la mecánica o modus operandi de estas narraciones 
[...] abandona(n) lo que hemos definido como la segunda condición de lo fantástico: la vacilación representada en el interior del texto [...] Desde las primeras frases del relato, el cuento neofantástico nos introduce, a boca de jarro, al elemento fantástico: sin progresión gradual, sin utilería, sin pathos. (Alazraki 1990: 28 - 30)

Alazraki indica certos pontos que achamos importantes para o nosso estudo. Aponta que o gênero neofantástico elimina a exclusividade do caráter negativo do elemento fantástico. No fantástico tradicional os acontecimentos sobrenaturais ocupam sempre o primeiro plano da narrativa. No neofantástico, as estratégias narrativas procuram colocar no primeiro plano a atitude das personagens frente ao acontecimento sobrenatural, a sua "não perturbação" frente aos acontecimentos sobrenaturais. Assim, o neofantástico implica, talvez, um maior grado de sofisticação, questionando a realidade que se esconde detrás da realidade narrada. O mistério oculto que se esconde em alguma parte do mundo racional não mais interrompe na quotidianidade para provocar o temor, mais bem-dito, esconde-se detrás da realidade, às vezes transpassando as suas fronteiras para alargar a perceção desta.

Partindo da hipótese de que os elementos fantásticos que aparecem na obra de Ungulani Ba Ka Khosa formam parte de uma mundividência específica de origem tradicional africana, consideramos importante dedicar algumas palavras ao tema da dicotomia entre a tradição e a modernidade na narrativa moçambicana moderna.

Para Francisco Noa, esta dicotomia desempenha a função de "uma das dimensões mais representativas e estimulantes [...] onde se flagram as indefinições, os conflitos, as crises identitárias e existenciais e as dinâmicas constitutivas das próprias sociedades e do imaginário que as singulariza” (Noa 2008: 12). A relação entre a tradição e a modernidade é um tema frequentemente tratado nas obras dos escritores moçambicanos contemporâneos. Basta mencionar os autores já consagrados do cânone literário moçambicano como Mia Couto, Paulina Chiziane, e Ungulani $\mathrm{Ba} \mathrm{Ka}$ Khosa, entre outros. Também é necessário acrescentar que o trabalho da crítica literária dedicado a esta problemática tem sido já bastante prolífero ${ }^{1}$. Existe entre os críticos um consenso, segundo o qual o tema de oposição entre a tradição e a modernidade, na literatura moçambicana, deriva da tendência de tematização da oralidade africana no período pós-colonial, em que o objetivo era romper com a hegemonia estética do cânone literário da antiga metrópole. A literatura moçambicana, profundamente marcada pela situação pós-colonial e pela presença de modelos literários recebidos quer da metrópole, quer do estrangeiro, no processo da construção da sua própria estética procurou modelos da tradição oral, tida como um elemento autenticamente africano (Matusse 1998: 74). Com a dupla herança cultural construiu um discurso mesclado, híbrido, que visa abranger esta realidade heterogénea. Francisco Noa, no que diz respeito a este tema, explica:

Em relação às nossas literaturas, a sua especificidade reside na oscilação, confronto ou conciliação entre uma visão do mundo de matiz claramente ocidental e nos múltiplos assomos estéticos e temáticos ligados, muitas vezes, à perseguição de uma pretensa ou original mundividência negro-africana que a alimenta e estrutura. [...] Por outro, a pulsação de um substrato mundividencial ligado às origens, latentes ou mistificadas, ancorado na reinvenção das tradições e de marcas vivenciais 
particulares que implicam o retorno ou a procura de universos que perturbam inevitavelmente a ordem legisladora da modernidade dominada pelo logocentrismo. (Noa 2008: 23)

A oralidade nas narrativas moçambicanas manifesta-se, por um lado, no nível estético. Os escritores alteram a sintaxe e o vocabulário do português-padrão para "moçambicanizar" a sua escrita. No entanto, a influência da oralidade vai mais além das estratégias textuais, manifestandose também na tendência de resgatar o mundo tradicional no nível temático. Daí resulta o uso e a tematização do imaginário tradicional africano, cujo caráter é vinculado às crenças animistas, e a subsequente utilização de motivos fantásticos de índole animista. A sua função é, precisamente, apoiar a autenticidade da lógica tradicional no âmbito da narrativa e incorporá-la, deste modo, na estética herdada do colonialismo.

Como constata Ana Margarida Fonseca, a "presença de elementos perturbadores da separação, consensualmente aceite no Ocidente, entre racional e irracional, real e mágico, verdadeiro e fantasioso" é um dos fatores frequentemente detetáveis nas narrativas moçambicanas. Conforme a autora, os elementos que ela considera mágicos ou maravilhosos contribuem para o debate acerca da mestiçagem nos espaços pós-coloniais (Fonseca 2006: 13).

De acordo com Maria Fernanda Afonso, a enfatização do passado mítico africano nas obras literárias é "uma forma de protesto contra o racionalismo do ocupante" (Afonso 2004: 351). Em continuação, podemos afirmar que a coexistência de duas ordens de racionalidade, resultante da revelação do fantástico mítico africano, escondido detrás de um mundo construído conforme as regras racionais, é uma das características às quais a narrativa moçambicana pós-colonial recorre frequentemente. Por um lado, os autores demonstram uma grande preocupação com o realismo e constroem os seus espaços narrativos profundamente ancorados na realidade moçambicana, nos seus problemas sociais, contradições e histórias, e abrem temas problemáticos da sociedade contemporânea. Por outro lado, este realismo é interrompido pelos elementos da ordem irracional e sobrenatural, que refletem o imaginário da cosmovisão tradicional africana.

Ao analisar os elementos do fantástico na literatura moçambicana, não podemos resistir perante a possibilidade de mencionar uma interessante proposta: a de classificá-los como característicos de um novo gênero literário. $O$ seu carácter animista levou alguns críticos a falarem sobre o aparecimento de um gênero literário que denominaram de "realismo animista" ${ }^{2}$. Neste trabalho não pretendemos refletir sobre a existência ou não do tal gênero, não obstante, parece-nos importante a tentativa de alguns pesquisadores de sublinhar a especificidade ou autenticidade do elemento fantástico africano ${ }^{3}$.

No trabalho dedicado à construção da moçambicanidade na literatura, Gilberto Matusse defende o caráter particular do fantástico moçambicano da seguinte maneira:

2 O termo apareceu pela primeira vez no romance Lueji (1989), do escritor angolano Pepetela. No romance as personagens refletem sobre a incapacidade dos brancos de entenderem a lógica do pensamento africano, devido ao fato de não compartilharem a religiosidade animista. Segundo eles os brancos, assim, não conseguem entender o realismo animista.

3 O termo aparece, por exemplo, em trabalhos de Luciana Morais da Silva, João Olinto Trinidade Júnior ou Silvio Ruiz Paradizo. 
Não existe um padrão válido para todas as civilizações a partir do qual se possa traçar uma fronteira entre o que é e não é fantástico. As nossas reflexões partem de uma visão do mundo assente no modelo racionalista ocidental, mas os universos retratados nas obras pertencem a civilizações onde imperam outros modelos de pensamento, outras crenças, enfim, outras concepções do que é a ordem natural. [...] o que os ficcionistas moçambicanos pretendem é [...] demarcar-se da tutela absolutista do racionalismo ocidental, através da simulação da adopção de um imaginário africano, ou do cruzamento de ambos [...]. (Matusse 1998: 171)

Dentro dos motivos fantásticos característicos ou, pelo menos, frequentemente recorridos da literatura moçambicana, é preciso salientar o lugar ocupado pelos antepassados. O mundo da narração costuma ser influenciado por uma força que provém de um mundo invisível, mas capaz de atuar no mundo tangível. Os defuntos participam na diegese punindo ou ajudando os vivos, continuando a controlar a vida e o mundo deles. Podem atuar como uma personagem concreta em forma visível, mais física, ou como uma força mais abstrata que vigia os acontecimentos sem aparecer fisicamente. No entanto, nos dois casos os espíritos dos antepassados simbolizam, em geral, uma força protetora das tradições. Se estas não são respeitadas, as personagens do mundo real sofrem consequências. A punição tem caráter do fantástico que irrompe no mundo dominado pela lógica racional.

A ligação entre o mundo dos vivos e o mundo dos mortos é assegurada através dos feiticeiros, conhecedores das regras tradicionais estabelecidas. São capazes de interpretar as forças não-visíveis e de, através de rituais mágicos, reestabelecer ou desintegrar a ordem. Os motivos fantásticos nas obras moçambicanas costumam aparecer dentro do âmbito da atuação dos espíritos dos antepassados. Por isso, manifestam-se, frequentemente, representados pelo aparecimento dos mortos no mundo dos vivos em forma de espíritos, pelos rituais mágicos que as personagens exercem, ou pela atuação de seres míticos.

A obra do escritor moçambicano Ungulani Ba Ka Khosa enquadra-se dentro da corrente de resgate de valores tradicionais, marginalizados por causa do processo de colonização. A sua escrita literária surge no período da pós-independência, caracterizado pela criação literária mais heterogênea e crítica, liberada da sua função de apoiar a luta pela independência. Na sua obra, Khosa examina a formação da identidade híbrida moçambicana e tende a introduzir o tema de resgate do imaginário tradicional, amiúde focalizando os episódios da história moçambicana. Segundo a opinião de Gilberto Matusse, Khosa explora até obsessivamente o tema do contraste entre a tradição e a modernidade (1998: 143).

Em Ualalapi, o autor constrói a narrativa ao redor da personagem histórica de Nhungunhane, o último imperador de Gaza, região que se situa no sul de Moçambique. A história revisita alguns episódios do seu reinado (1884 - 1895), desde a sua ascensão ao trono até ao declínio e a queda do império $n g u n i^{4}$ em Moçambique. Ngungunhane acabou por ser derrotado e capturado pelos portugueses, a seguir foi transportado ao exílio para Portugal e, posteriormente, para os Açores onde ele faleceu. O romance apresenta traços da metaficção historiográfica, conceito que foi definido por Linda Hutcheon na Poética do Pós-Modernismo: História, Teoria, Ficção (1988):

4 Etnia que veio a Moçambique do território da África do Sul no início do século XIX sendo, por isso, considerada como um elemento invasor no território moçambicano. 
Com esse termo, refiro-me àqueles romances famosos e populares que, ao mesmo tempo, são intensamente auto-reflexivos e mesmo assim, de maneira paradoxal, também se apropriam de acontecimentos e personagens históricos [...] sua autoconsciência teórica sobre a história e a ficção como criações humanas (metaficção historiográfica) passa a ser a base para seu repensar e sua reelaboração das formas e dos conteúdos do passado. (Hutcheon 1991: 21-22)

Consideramos importante mencionar este conceito dado que no romance o autor aborda um tema histórico de uma maneira específica: a imagem do Ngungunhane foi elevada ao nível de um herói nacional no período da pós-independência, como um símbolo do povo moçambicano a se opor à colonização portuguesa. No entanto, a narrativa não se encaminha para uma contemplação de um símbolo da resistência; mais bem questiona a veracidade deste discurso oficial criado sobre Ngungunhane contrariando-o com uma ficção que subverte a imagem positiva do hosi, palavra da língua tsonga que significa o rei. Este é retratado como um tirano, um déspota, um governador cruel que abusava do seu poder. Khosa aproveita as fontes de informação históricas, faz uso de personagens históricas do Império da Gaza, parte de uma realidade histórica não ficcionada; e em conseguinte questiona, reinventa e altera a leitura e a interpretação oficiais do passado (Leite 1995: 54). Desafia a perspetiva da história oficial, desconstrói a imagem desta personagem consagrada pelo discurso do poder propondo a imagem negativa de Ngungunhane que se baseia nas fontes provenientes da tradição oral. Os testemunhos oficiais e os provenientes da oralidade intercalam-se por toda a extensão da narrativa, formando assim uma perspetiva multifocal que por um lado fundamenta a verossimilhança do romance, pelo outro abre o questionamento da veracidade do discurso histórico. Em Ualalapi portanto, podemos encontrar os procedimentos mencionados por Hutcheon como característicos para a metaficção historiográfica. No processo de reescritura, apoiando-se na oralidade tradicional, Khosa retoma o mundo repleto de tradições e mitos moçambicanos, em que os acontecimentos fantásticos de carácter animista coexistem com a realidade racional.

Khosa afirma, numa entrevista concedida a Michel Laban, a sua intenção de desconstruir o mito que o discurso do poder construiu sobre Ngungunhane: "era necessário tirar o mito e dar a versão que a gente ouvia pelos avós, pelas pessoas mais velhas, de que Nhungunhane não foi assim aquela pessoa que estão a idealizar, mas que realmente foi um ditador" (Laban 1998: 1070).

A desconstrução da personagem criada pelo discurso oficial começa já a partir das citações das fontes históricas, bastante eloquentes relativamente às intenções do autor, indicadas logo no início do romance. As citações contradizem-se ao descrever o aspeto físico e o caráter do imperador, ora ressaltando as suas qualidades, ora os defeitos: "Só direi que admirei o homem, discutindo durante tanto tempo com uma argumentação lúcida e lógica... (Ayres d’Ornellas)”; “... mas toda a sua política era de tal modo falsa, absurda, cheia de duplicidade, que se tornava difícil conhecer os seus verdadeiros sentimentos. (Dr. Liengme)" (Khosa 2018: 11). A seguir deparamo-nos com a citação da autoria de Augustina Bessa Luís: "A história é uma ficção controlada" (Khosa 2018: 11). O autor aponta, desta maneira, para a finalidade de desenvolver um jogo de diferentes leituras possíveis do passado, visto que este sempre é escrito conforme as circunstâncias e as relações de poder.

O romance consta de seis capítulos que têm uma estrutura independente. Poderiam funcionar como contos isolados, contudo são conectados por meio da personagem do hosi. Estes capítulos 
focalizam várias personagens que diretamente ou indiretamente interagem com ele, de maneira que chegamos a saber quem ele foi e o que cometeu durante a sua vida através do olhar dos outros. A construção da personagem na narrativa não é definida diretamente pelo narrador, tendo assim o leitor espaço para fazer a sua própria interpretação. A narrativa revela as atrocidades, a brutalidade e o abuso de poder cometidas por parte do imperador, tornando-o assim uma personagem que atua como opressor, portanto, uma figura anti-heroica.

Cada um dos capítulos aparece introduzido por um texto curto, denominado "Fragmentos do fim”, que funciona como um contraponto mais realista ao capítulo que se segue. Estes textos são documentos históricos que, de alguma maneira, se referem ao período do governo de Ngungunhane ou, textos fictícios que descrevem episódios deste período histórico, às vezes através do recurso à parodia. Os capítulos, ao contrário, têm um carácter mais fictício, mítico, são uma clara invenção. O autor, desta forma, estrutura o romance conforme dois discursos opostos: o discurso oficial do poder, ou, um texto que parece ter mais valor histórico, e o discurso herdado através da tradição oral. A partir da alternância entre os dois discursos podemos perceber que o autor se concentra na dicotomia entre a tradição e a modernidade.

Semelhantemente a outros romances moçambicanos, também em Ualalapi há, no plano temático, uma ênfase na tradição oral e nos valores culturais moçambicanos. Enfatizar o substrato cultural tradicional é a maneira como os escritores destacam a moçambicanidade nas suas obras. Nelas podemos observar a presença frequente das práticas ou crenças tradicionais moçambicanas e a cosmovisão animista do mundo. Estes elementos, que fogem à lógica racional ocidental, são representados, na obra de Khosa, dentro de uma estrutura formada pelos motivos da transgressão das regras e da conseguinte punição. Gilberto Matusse a este respeito observa:

Em Khosa, o acontecimento sobrenatural está quase sempre ligado a um acontecimento particular, que interfere no equilíbrio da vida da sociedade ou de um indivíduo. Aparece como efeito (por exemplo, punição de uma transgressão ao código de conduta), ou como sinal desse acontecimento (como prefiguração ou como simples indicação). (Matusse 1998: 172-173)

Como o romance gira em torno da cosmovisão animista do mundo, a punição é executada pelos espíritos dos antepassados e aparece em forma de eventos sobrenaturais. Em Ualalapi, a punição manifesta-se em forma de eventos climáticos enigmáticos ou como uma intervenção no funcionamento biológico dos protagonistas/das personagens. É importante sublinhar que o efeito fantástico em Khosa se fundamenta na hiperbolização dos fenómenos naturais ou dos processos biológicos. Vejamos agora uns exemplos concretos.

No romance observa-se a presença de uma força sobrenatural, onipresente, que governa as ações das personagens. A atmosfera de mau agoiro, que dirige a narrativa para um apocalipse, é desenhada a partir do primeiro capítulo, através das aparições de animais que na tradição moçambicana têm um significado negativo. Ualalapi, personagem que cede o nome ao romance, é um guerreiro da corte real que é designado para matar Mafemane, irmão de Ngungunhane e o legítimo herdeiro do trono, depara no caminho para casa com dois pangolins, "animais de mau agoiro" (Khosa 2018: 19). Mais tarde, quando entra numa aldeia que parece estar deserta, uma mulher explica-lhe: "Os mochos teimaram em serandar sobre as casas, chiando a toda a hora e trazendo os espíritos há muito adormecidos que perturbaram as nossas mentes e deram a morte 
a alguns [...]" (Khosa 2018: 21). As previsões apocalípticas continuam a dirigir a narrativa. No sonho, a mulher de Ualalapi antevê a morte da família, no caso de o marido aceitar a matar Mafemane:

- Tive sonhos esquisitos.

- É normal em dias de luto.

- Sonhei com a tua morte.

- Minha morte?

- Sim.

- Como é que morri no sonho?

- Morreste andando. A tua voz sustinha o teu corpo sem vida. Eu e o teu filho morremos afogados pelas lágrimas que não paravam de sair dos nossos olhos. (Khosa 2018: 26)

Ualalapi, apesar de hesitar, cumpre o seu dever para com o futuro hosi e assassina Mafemane. Comete, desta forma, a primeira de uma série de transgressões das regras estabelecidas. É punido pelo seu crime; ele foge para a floresta enlouquecido, cheio de remorso, chorando e gritando um "não" que se espalha pela terra durante onze dias. A sua família é morta como foi previsto: "Minutos depois o choro de uma mulher e uma criança juntaram-se a um «não» e ao ruído da floresta a ser arrasada. E o mesmo ruído cobriu o céu e a terra durante onze dias e onze noites, tempo igual à governação, em anos, de Ngungunhane [...]" (Khosa 2018: 29). Este episódio inicial estabelece a estrutura que se mantém ao longo da narrativa: a estrutura em que as regras estabelecidas são transgredidas e em que as forças invisíveis, que desde o fundo dirigem o mundo narrado, punem a transgressão de forma sobrenatural.

Acontece toda uma série de infortúnios que as personagens sofrem como punição por causa da transgressão das regras. A narrativa ganha, deste modo, o carácter de um mito apocalíptico sobre a queda do império nguni. É interessante observar como muitas vezes o fantástico é ligado aos líquidos corporais. Há dois momentos, por exemplo, nos quais o autor se refere à menstruação feminina. O primeiro é representado por um comentário do narrador:

Ngungunhane [...] fumava mbhangui, nome que leva a canábis espontânea, muito fumada pelos Tsongas, pensando na desventura que tocara a sua casa, pois as suas trinta mulheres, espalhadas pela capital, há mais de quatro semanas que vertiam sangue pelas coxas, facto inédito na sua vida de casado e polígamo [...]. (Khosa 2018: 37)

A segunda referência, mais significativa já que é o motivo ao redor do qual é construída a narração, encontramos no capítulo intitulado "Damboia". Damboia é uma tia do imperador, que violava as regras sociais fuzilando vários homens que não queriam satisfazer os seus desejos sexuais. Ela morre "de uma menstruação de nunca acabar ao ficar três meses com as coxas toldadas de sangue viscoso e cheiroso que saía em jorros contínuos [...]” (Khosa 2018: 41). O sangue menstrual de Damboia envenena os rios e os poços, morrem peixes, os crocodilos passam a viver nas margens, cai uma chuva anormal. Todos os acontecimentos indicam uma catástrofe posterior: 
Ao amanhecer começou a cair uma chuva amarela, forte, de gotas grossas e pegajosas como baba de caracol [...]. Na aldeia real havia sol e vento calmo. Nos primeiros dias era normal ver Ngungunhane dirigir-se aos arredores, acompanhado pelos maiores do reino, e contemplar aquela chuva azeda, apelando para a calma [...]. Ao quarto dia os homens da corte refugiaram-se nas casas e deixaram de aparecer à rua. Um fenómeno estranho passava-se nos arredores: cadáveres sem nome e rosto apareceram à superfície das águas lodosas, se é que era água aquele líquido pastoso e espesso. (Khosa 2018: 41)

Os feiticeiros da aldeia concluem que os cadáveres são de outros tempos e apareceram porque "vieram chamar a atenção àquele povo que nada respeitava" (Khosa 2018: 41). É explicitado neste trecho que a punição é executada por não ser respeitada a tradição. O fantástico manifesta-se através da punição particular de Damboia e pelo desabamento da chuva estranha que pune a comunidade inteira por causa do desrespeito à tradição.

Outro exemplo do fantástico, ligado aos líquidos corporais, aparece no episódio dedicado ao filho do imperador, Manua. Ele estudou em Portugal, e na narrativa é retratado como um grande admirador dos brancos e dos seus costumes. No primeiro dia da sua viagem a Portugal ele comeu peixe, comida proibida para os ngunis. Assimilou-se, aceitou a cultura dos inimigos e cometeu a transgressão das regras culturais do seu povo. Por isso é punido:

[Manua] Puxou os lençóis para o lado esquerdo, saltou da cama e, já junto à porta, sentiu algo viscoso e escorregadio a colar-se às plantas dos pés. Arroz em pasta cobria o soalho [...]. Um fio que ia alargando até ocupar a extensão do corredor saía do camarote. Era o vómito. Eram cabeças de peixes. Era o cheiro. Eram as moscas a zumbir. [...] O mar, em redor do barco, tomava a cor do vómito. (Khosa 2018: 63-64)

Notemos como o autor é capaz de criar imagens violentas, chocantes. Parece-nos que a força destrutiva do insólito é reforçada pela brutalidade da língua. O autor é bastante explícito nestas cenas. O barco em que Manua viaja fica todo coberto com o seu vómito. A sua punição por ter violado a tradição torna-se ainda mais estranha: "O pénis minguava de dia para dia. No dia da sua morte acordou sem nada entre as coxas e apanhou a maior bebedeira de sempre” (Khosa 2018: 69). Manua morre esquecido pelo seu pai por aceitar a cultura dos brancos.

A chuva é mais um motivo fantástico que se repete e que aparece como uma força destrutiva. Já mencionámos a chuva no capítulo "Damboia”. A chuva também acompanha a morte de Domia, filha de um guerreiro da corte, acusado, injustamente, de insultar a rainha. Foi morto apesar da sua inocência e Damia decide vingar-se da morte bárbara do seu pai. Pretende apunhalar o rei, mas não o consegue, apenas lhe causa uma pequena ferida na coxa. No momento da sua morte desaba do céu uma chuva estranha:

Quando a chuva desabou, Domia deu o último suspiro, deixando a carne a ser desfeita pela chuva que não parou de cair durante semanas até que sobre a terra não restasse um osso. E o rei passou o resto da vida contemplando, a sós, o sulco que não mais se apagaria do corpo fizesse o que fizesse. (Khosa 2018: 38) 
O romance termina com o capítulo intitulado "O último discurso de Ngungunhane" em que o imperador, já capturado pelos portugueses, profetiza os detalhes da futura colonização portuguesa. O apocalipse, que foi indicado várias vezes, é levado ao fim, Ngungunhane é capturado e levado para Portugal, o que significa o final do império.

Vimos que o romance Ualalapi, cujo objetivo central é o questionamento da veracidade do discurso do poder e a desconstrução do mito sobre a figura histórica do último imperador de Gaza, apresenta vários elementos que podemos classificar como fantásticos. A narrativa representa um mundo que está a desintegrar-se por causa do desrespeito aos valores tradicionais e às normas éticas e morais, o que leva à punição. Esta punição é realizada por meio de eventos de uma outra ordem, eventos que no pensamento racional são percebidos como impossíveis ou sobrenaturais. Os fenómenos desta índole enquadram-se na lógica mítica da cosmovisão africana, em que impera o domínio dos espíritos, e têm, por tanto, um caráter animista. Os elementos fantásticos são frequentemente construídos através da hiperbolização de elementos naturais, que podem ser ou eventos climáticos ou interferências no funcionamento do corpo humano. O fantástico na narrativa é apresentado em forma de punições particulares que levam a um apocalipse final, protagonizado pelos espíritos que penetram no mundo por causa da transgressão da tradição.

O fantástico em Ualalapi coincide com o conceito do "neo-fantástico" proposto por Jaime Alazraki ao funcionar como uma máscara graças à qual a narrativa revela a existência de forças escondidas por detrás dela. Além disso, estas forças, apesar de serem temidas, não desempenham a função de um invasor no mundo narrado. Elas são produto da atuação dos seres que habitam um mundo paralelo ao mundo racional. Não produzem surpresa, não provocam temor, não assumem o papel do tema central do romance, mais bem acompanham o mundo narrado, sendo a sua parte inseparável.

\section{Referências bibliográficas}

Afonso, M. F. (2004). O conto moçambicano: Escritas pós-coloniais. Lisboa: Caminho.

Alazraki, J. (1990). ¿Qué es lo neofantástico? Mester, XIX (2), 21-33.

Fonseca, A. M. (2006). Desafios da mestiçagem: O realismo mágico em questão. Veredas, 7, 13-29.

Hutcheon, L. (1991). Poética do pós-modernismo: história, teoria, ficção. Rio de Janeiro: Imago ed.

Khosa, U.B.K. (2018). Gungunhana. Porto: Porto editora.

Laban, M. (1998). Moçambique - Encontro com escritores, III vol. Porto: Fundação Eng. António de Almeida.

Leite, M. (1995). A dimensão anti-épica da moderna ficção moçambicana: Ualalapi de U. B. K. Khosa. Discursos, 9, 53-69.

Matusse, G. (1998). A construção da imagem da moçambicanidade em José Craveirinha, Mia Couto e Ungulani Ba Ka Khosa. Maputo: Livraria Universitária, UEM.

Noa, F. (2008). A Letra, a sombra e a água - Ensaios e dispersões. Maputo: Texto Editores.

Salvador, A. G. (1984). De lo fantástico y de la literatura fantástica. Anuario de estudios filológicos, VII, 207-226. Todorov, T. (2007). Introdução à literatura fantástica. São Paulo: Perspectiva. 